\title{
Characterization of the Key Material for Elimination of PM2.5 Particles in the Atmosphere
}

\author{
Bo Qiu, Qingshan Li, Wei Hong, and Guangzhong Xing \\ State Key Laboratory of Metastable Materials Science and Technology, Yanshan University, Qinhuangdao 066004, China \\ Correspondence should be addressed to Bo Qiu; 1755839034@qq.com
}

Received 6 July 2014; Revised 12 September 2014; Accepted 14 October 2014

Academic Editor: Xinqing Chen

Copyright (C) 2015 Bo Qiu et al. This is an open access article distributed under the Creative Commons Attribution License, which permits unrestricted use, distribution, and reproduction in any medium, provided the original work is properly cited.

\begin{abstract}
In recent years, with the gradual deterioration of air quality and with the more and more frequency of haze weather phenomenon, it intrudes into the human body and brings great harm to human health when people are unprepared. The basic theory that anion could purify air and eliminate positive ion explains that anion balata modified bitumen could reduce PM2.5, and the number of anion pavement release relates to the air purification. At the same time, building materials plaza and pavement materials with many functions were designed which can release negative ions, eliminate PM2.5 particles, and decompose harmful components of fuel vehicle exhaust.
\end{abstract}

\section{Introduction}

There are 30 areas, cities, and provinces, which were shrouded in the four-haze process in January 2013. However, there were only five days without haze in Beijing [1]. The report shows that only less than $1 \%$ of cities have achieved air quality standards recommended by the World Health Organization (WHO). At the same time, seven of the world's ten most polluted cities are in China. The gradual deterioration of air quality and more and more frequency of haze weather phenomenon would cause respiratory diseases, cardiovascular system, blood system diseases, reproductive system diseases, and so forth, when people are not prepared, for example, sore throat, emphysema, asthma, rhinitis, bronchitis, and other symptoms. It will lead to lung cancer, myocardial ischemia, and reperfusion injury in the long term in this environment. The main components of the haze are sulfur dioxide, nitrogen oxides, and particulate. The first two belong to the gaseous pollutants; particulate matter is finally a heavier fog and haze pollution culprit. There are toxic particulate matter sources in cities. First, it is the automobile exhaust. Second, it is exhaust gas burning coal for the winter heating in the north, and industrial production emissions, such as metallurgy, furnace or boiler, electrical, mechanical manufacturing industry, and a large number of automotive paint and building materials production furnace combustion emissions. Finally, dust was caused by the construction sites and road traffic.

The negative ions in the air are called air vitamin, environmental health guardian, which can purify the air. It is beneficial to human health $[2,3]$. The negative ion in the air is a single molecular and light ion clusters. The negative ion mainly includes hydroxide ion, oxygen anion, and carbonate ion, but the proportion of oxygen anion is large and relatively stable. In nature, the source of negative ions is mainly to stimulate the universe, sun rays, and radioactive elements in rock and soil release radiation as well as the lightning excitation, storm, waterfall, the wave friction, and other factors. In addition, the decomposition of rain water and forest and plant photosynthesis made more oxygen-enrich air.

However, artificial negative ion mainly uses high voltage electrostatic field, high frequency electric field, ultraviolet radiation, and radiation to hit water in order to make the air ionization and produce negative ion. In recent years, people found that some inorganic oxide composite powder induced negative ion in the air; some rare earth compound salt also has led to the air ionization function. The negative ions in the air have a positive effect on the growth of the body and preventing disease.

(1) Anion can improve the lung organ function and respiratory villi cleaning efficiency. (2) Aoion can reduce blood 
pressure and enhance myocardial function. (3) Anion can reduce strong oxidation. Negative oxygen ions can destroy bacteria's cell membrane or the activity of cells bioplasm active enzyme, so as to achieve the purpose of antibacterial sterilization. (4) Aoion can encourage people's spirit. It could increase body alertness and enhance people's imagination, which could improve work efficiency at the same time. (5) Aoion can strengthen the immune system function. The results of the study show that nocturnal sleep in pyjamas with negative ion emission function will reduce to some extent the rectal temperature of the human body, improve the quality of sleep, and improve human immunity [4-6]. Thus, negative ion and human health are closely related, especially in the increasing pollution today.

At present, PM10 is one of the important general pollution indices in the assessment of atmospheric environment quality. When the environment aerodynamic diameter is less than $2.5 \mu \mathrm{m}$, it is called PM2.5 [7, 8]. At present, people gradually realize that the particle size under the $10 \mu \mathrm{m}$ endangers the environment and human health; in particular, PM2.5 pollution is the most serious one. In this paper, Gu Haiyan is adopted for nanometer ion additive to prepare road asphalt material. Gu Haiyan not only looks gorgeous but also has nano-single crystalline, nanosphere, nanofiber, and nanosheet layer. Of course, the important function is to release anions. Gu Haiyan can radiate infrared light with a wavelength $8-15 \mu \mathrm{m}$ at ambient temperature $20^{\circ} \mathrm{C}$, and the normal emission rate is 0.88 . Since far infrared ray is very close to vibration frequency of human body cellular elements, as long as "Life waves" permeate into the body, it will cause resonance between atoms and molecules in human cells, through the resonance absorption and the heat after the friction between molecules and it will form thermal reaction, thereby promoting the rise of subcutaneous deep temperature, expanding blood capillary, and accelerating the blood circulation. It is beneficial for clearing vascular accumulation and the harmful substances of the body, removing obstruction to hinder metabolism, and reviving the organization. And then it will promote the generation of enzyme in order to activate cells, prevent aging, and strengthen the immune system. Therefore Gu Haiyan is a kind of precious stone and natural nanomineral materials.

\section{Main Materials and Methods}

2.1. Main Materials. Recycled rubber powder, $20-100 \mu \mathrm{m}$ in diameter, was obtained from Fang da huang yu Co., Ltd., Donguan. Anion additive: the anion additive of rubber modified asphalt is Gu Haiyan produced in Baotou city of Mongolia of China in this paper which is a kind of sedimentary rocks and belongs to Yellow River basin.

\subsection{Characterization of Scanning Electron Microscope (SEM).} Figure 1 is SEM images of Gu Haiyan.

Because of the specific geographical environment, coles contacting between particles, mainly point-line contacting with medium. In the process of formation rock, a series of diagenetic reactions between sedimentary components with
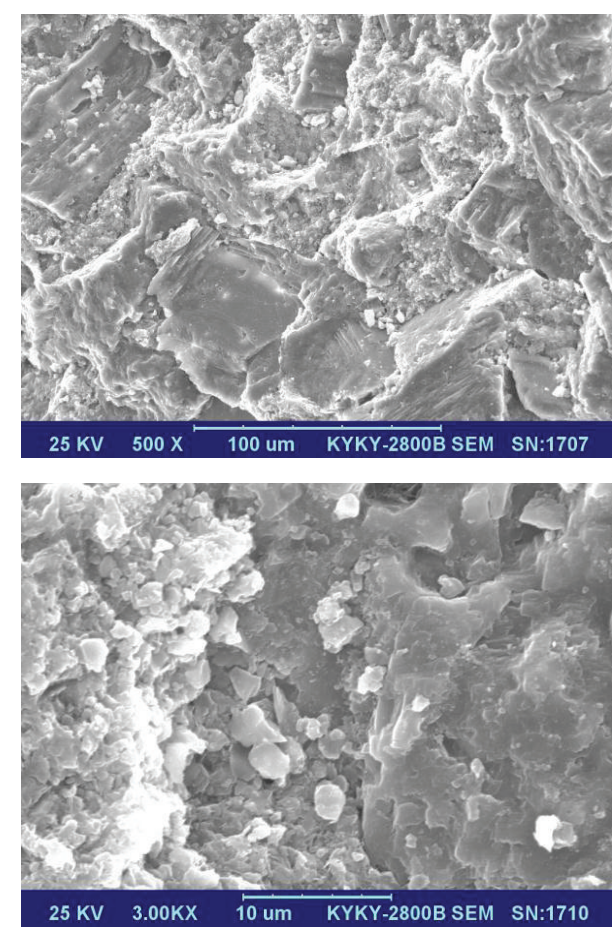

Figure 1: SEM images of Gu Haiyan.

pore takes place. Such structure for $\mathrm{Gu}$ Haiyan surface has good interfacial energy; when contacting with other polymers, it can increase the stability.

2.3. Fourier Transform Infrared Spectroscopy (FTIR). Figure 2 shows the FTIR spectra of the Gu Haiyan. The main characteristic peaks are $1035 \mathrm{~cm}^{-1} \sim 1108 \mathrm{~cm}^{-1}, 1441 \mathrm{~cm}^{-1}, 1841 \mathrm{~cm}^{-1}$, $2530 \mathrm{~cm}^{-1}$, and $2905 \mathrm{~cm}^{-1}$. The $1035 \mathrm{~cm}^{-1} \sim 1108 \mathrm{~cm}^{-1}$ belong to strong peak of S perssad. $1441 \mathrm{~cm}^{-1}$ is crystal water peak, $1814 \mathrm{~cm}^{-1}$ is absorb water peak, and $2530 \mathrm{~cm}^{-1}$ is $\mathrm{S}-\mathrm{H}$ perssad, which is weaker than $\mathrm{O}-\mathrm{H}$ absorption band. The frequency of $\mathrm{S}-\mathrm{H}$ perssad is not low when it forms hydrogen. $2905 \mathrm{~cm}^{-1}$ is $\mathrm{C}-\mathrm{H}$ perssad of the methylene.

2.4. Analysis of XRD. Figure 3 depicts the XRD pattern of $\mathrm{Gu}$ Haiyan. From the XRD diffractogram of Gu Haiyan five peaks at $2 \theta$ value of $26.73^{\circ}, 31.03^{\circ}, 41.14^{\circ}, 50.6^{\circ}$, and $51.06^{\circ}$ have been observed. These can be assigned to $31.03^{\circ}$ (104) plane of $\mathrm{CaMg}(\mathrm{CO} 2)_{3}, 41.14^{\circ}$ (113) plane of carbon, and $50.6^{\circ}(018)$ and $51.06^{\circ}$ (116) planes of $\mathrm{CaZn}(\mathrm{CO} 2)_{3}$. However, $26.73^{\circ}$ is of containing $\mathrm{S}$ perssad, because Gu Haiyan is mixture, so we cannot be sure of its plane.

The result of Gu Haiyan is consistent with XRD and FTIR. Due to existing $\mathrm{O}-\mathrm{H}$ and $\mathrm{S}-\mathrm{H}$, under the action of outside world, it is easy to be knocked off electronic and generate negative oxygen ion with water vapor in the air. X-ray peak sharp is different; it was affected by temperature which is also different; through the action of high temperature and pressure, it can release negative ion. In addition, because the particle diameter of the anion additive is at the nanolevel, it is easy to release anion in the physical admixing process, and 


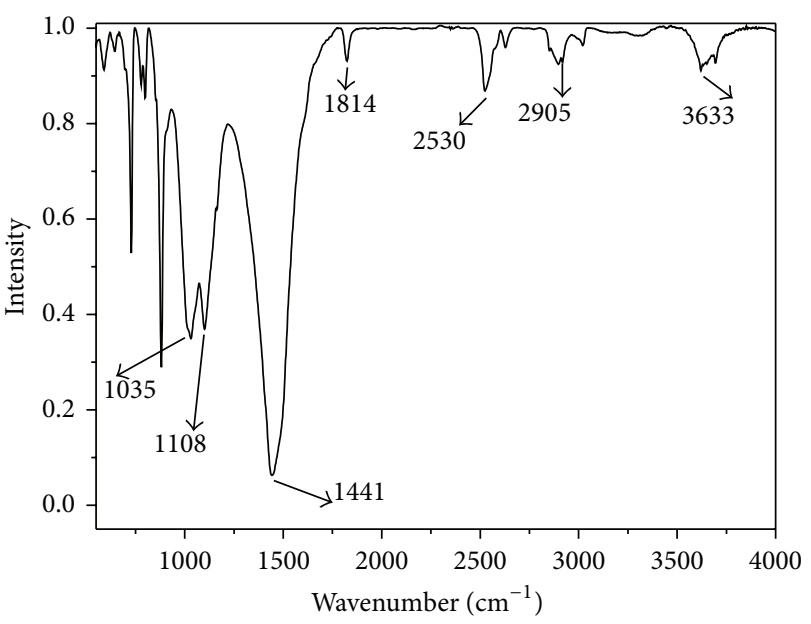

FIgure 2: FTIR of Gu Haiyan.

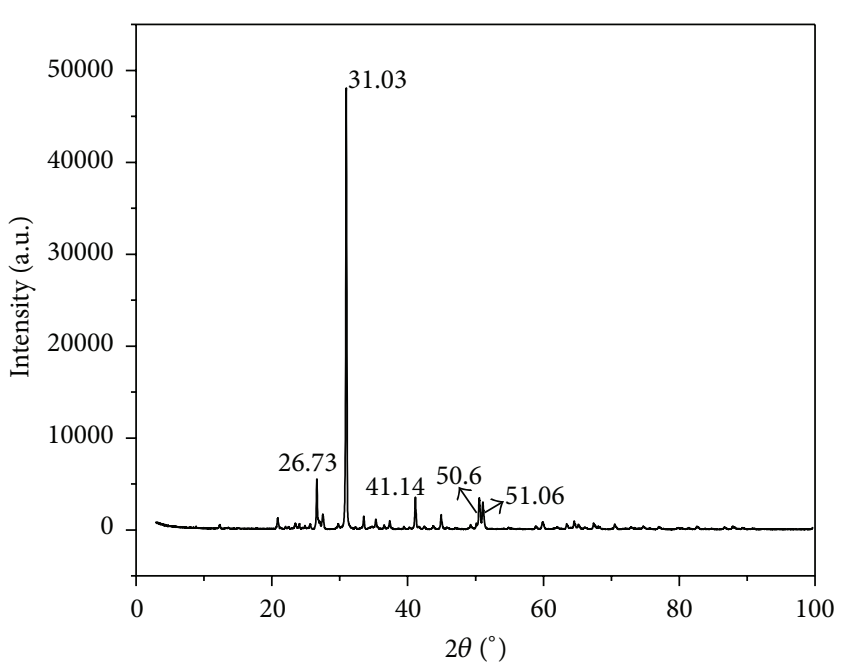

FIGURE 3: XRD of Gu Haiyan.

the miscible system is uniform and stable and thus suitable for productions.

2.5. Rubber Modified Asphalt Mixture Preparation. The latest micro/nanocontrollable preparation technology is to control the maximum particle below 5 microns. We developed the technology with the international advanced level which can control the particle size using the efficient equipment developed independently and a unique process, and the technology can adjust particle in the range of $0.2-5$ microns. So we successfully developed anion additive using this technology. Figure 4 is negative ion Gu Haiyan additive preparation process.

2.6. Composite Material Preparation. Melt a small amount of asphalt after adding recipes and additives, and then stir and warm it using a Magnetic stirrer [9-11]; then make it sheared with high shearing dispersing emulsifier at a temperature of $170^{\circ} \mathrm{C} \sim 190^{\circ} \mathrm{C}$ and speed of $4000 \mathrm{r} /$ minute $6000 \mathrm{r} /$ minute.

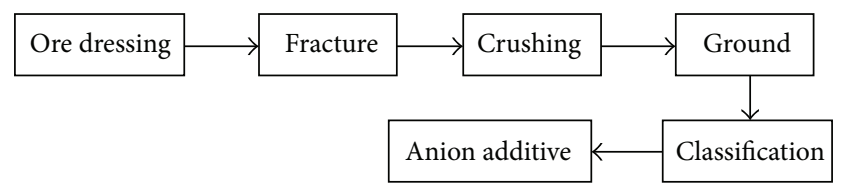

FIGURE 4: Negative ion additive preparation process.

After adding negative ions additives, cutting, cooling, and placing it for 30 minutes, then, it is the rubber modified asphalt of anion. It can be seen in the NMIR and IR that adding anion additive into rubber modified asphalt is a physical miscible process. There is only molecular interaction between the addictive and asphalt, and there is no chemical change which generates a new substance or group. Anion additives are made by opal and tourmaline material and others which can release negative ions [12].

2.7. Sample Performance Testing and Equipment. Testing of the asphalt, including designing the proportions of the mixture, evaluating its properties, and evaluating its road capability, was carried out in accordance with "Standard Test Methods of Bitumen and Bituminous Mixtures for Highway Engineering" (JTJ052-2000) and "Technical Specifications for Construction of Highway Asphalt Pavements" (JTG F402004). We then evaluated the anion release performance [1315]. Air ion detectors (DLY-6A232) were performed by Lianteng Electronic Co., Ltd., Zhangzhou, Fujian. X-ray diffraction (D-max-Bsystem) measurements were performed by Japan's Neo-Confucianism. FTIR (E55+FRA 106) measurements were performed by Germany Bruker Company.

\section{The Principle of the Relationship between Weakened PM2.5 and Negative Ions Bituminous Materials}

The research confirms many experts in the field of UN Air environmental, ecological level negative ions (small particle size anions) can capture dust pellets which will be agglomerated and precipitated and then remove effectively the dust of 2.5 and less 2.5 microns (PM2.5) and even one-micron particles in air which can reduce PM2.5 health hazards on human. The reason why ecological level negative ions purify the air is that ions are combined with airborne bacteria, dust, and smoke and gathered into a ball landing in order to eliminate PM2.5 hazards. Coincidentally, negative ions in the air are making Brownian motion without rules. However, Brownian motion itself is an effective way to eliminate the small dust. After anion binding particulates, it promotes Brownian motion and eliminates dust. Experiment shows that the smaller the diameter of particulates is, the more easily it is precipitated by anion. Water molecules in the air are moving without rules and imping on surface of composite material; under the action of external force, the outermost electrons of additives jump out of original track and combine with water vapor in the air or carbon dioxide, product negative oxygen ions. Figure 5 is a negative ion generation process. There are three main forms of negative ions purification of air. The first 
TABLE 1: The results of asphalt pavement anion test.

\begin{tabular}{llcccc}
\hline \multicolumn{2}{c}{ Sample name } & $\begin{array}{c}\text { Anion } \\
\text { concentration } \\
\max \left(\mathrm{a} / \mathrm{cm}^{3}\right)\end{array}$ & $\begin{array}{c}\text { Anion } \\
\text { concentration } \\
\text { average }\left(\mathrm{a} / \mathrm{cm}^{3}\right)\end{array}$ & Temperature ${ }^{\circ} \mathrm{C}$ & Relative humidity \% \\
\hline Rubber modified & Sample 1 & -1190 & -1076 & 20 & 50 \\
asphalt anion & Sample 2 & -1150 & -968 & -110 \\
Common asphalt & Sample 3 & -150 & -120 & 20 \\
\hline
\end{tabular}

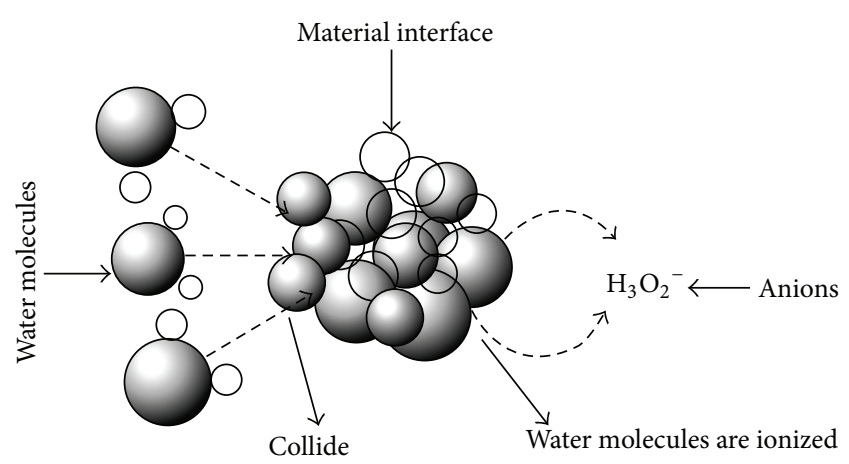

Anion generation method

FIGURE 5: A negative ion generation method.

method is that negative ions are adsorbed on the material surface, under the gravity, sinking gradually. The second is that negative ion is adsorbed in the material porosity and influenced by gravity, sinking gradually, so as to eliminate particles and purify air. The third is that neutralization reaction happens when negative ion is mixed with positively charged particles in the air; it can also have effect on elimination of particles. Figure 6 is anion purification principle.

\section{Result and Discussion}

Anion tire and road materials are designed in order to do the further research mechanism of anion adsorption and settling particles and friction with pavement. Energy saving and reduction mechanism are explored, in order to guide the engineering design and application of materials of anion. Through the research of rubber creep, heat resistance, friction, and aging experiments, they provide basic data for the design of roads.

In the release of negative ions, healthy environmentfriendly natural asphalt composite materials, there are 3 polymer species, such as SBS resin, polyacrylamide, recycled rubber, and polyacrylate copolymer; the additives are surfactants that can release negative ions; asphalt is petroleum asphalt, coal tar pitch; natural asphalt is cloth asphalt, Xinjiang Bitumen; fillers are inorganic compounds mixed with two or more kinds of fly ash, mineral ore, and construction waste powder; The natural anion asphalt composites technology is the same as the conventional asphalt mixing technology. Anion test

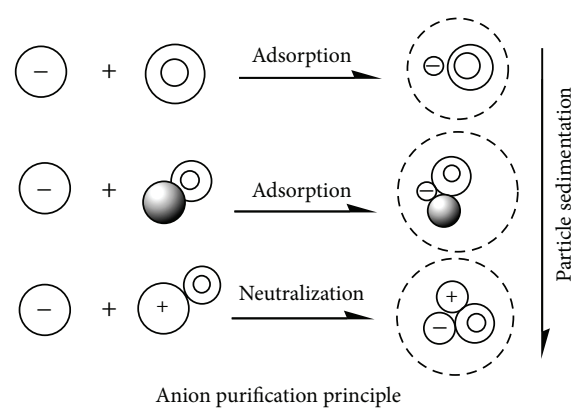

FIGURE 6: The anion purification principle.

of negative ion and general rubber modified asphalt road is shown in Table 1.

The test results prove that the rubber modified asphalt anion has good release negative ions, which can improve road dust and has a high value for weaking PM2.5.

\section{Conclusion}

Anion rubber modified asphalt material can release higher concentrations of air ions than ordinary materials and effectively purify the air. The purifying principle is that anions can capture dust pellets which will be agglomerated and precipitated and then remove effectively the dust of 2.5 and less 2.5 microns (PM2.5) and even one-micron particles in air which can reduce PM2.5 health hazards on human. But the work of purifying efficiency which is corresponding with the number of anions still needs to be further studied.

\section{Conflict of Interests}

The authors declare that there is no conflict of interests regarding the publication of this paper.

\section{References}

[1] J. Xu, G. A. Ding, and P. Yan, "It is from the analysis of component characteristics and sources of PM2.5 in Beijing area," Journal of Applied Meteorology, vol. 3, pp. 41-43, 2007.

[2] B. F. Yu, Z. B. Hu, M. Liu, H. L. Yang, Q. X. Kong, and Y. H. Liu, "Review of research on air-conditioning systems and indoor air quality control for human health," International Journal of Refrigeration, vol. 32, no. 1, pp. 3-20, 2009.

[3] W. X. Wang and J. J. Li, "Anion and its textiles influence on human," Henan Textile Science and Technology, pp. 2-4, 2002. 
[4] C. G. Sang and H. J. Zhong, "The research about anion fabric on natural fiber fabrics," Textile Science Research, vol. 17, pp. 47, 2007.

[5] Z. Xu, Y. Wu, F. Shen, Q. Chen, M. Tan, and M. Yao, "Bioaerosol science, technology, and engineering: past, present, and future," Aerosol Science and Technology, vol. 45, no. 11, pp. 1337-1349, 2011.

[6] S.-G. Lee, J. Hyun, S. Hwa Lee, and J. Hwang, "One-pass antibacterial efficacy of bipolar air ions against aerosolized Staphylococcus epidermidis in a duct flow," Journal of Aerosol Science, vol. 69, pp. 71-81, 2014.

[7] J. Wang, Z. M. Hu, and Y. Chen, "Contamination characteristics and possible sources of PM10 and PM2.5 in different functional areas of Shanghai, China," Atmospheric Environment, vol. 68, pp. 221-229, 2013.

[8] D. Mira-Salama, C. Grüning, N. R. Jensen et al., "Source attribution of urban smog episodes caused by coal combustion," Atmospheric Research, vol. 88, no. 3-4, pp. 294-304, 2008.

[9] C. S. Huang and X. Huang, "Purification of anion material," Clean and Air-Conditioning Technology, vol. 2, pp. 45-47, 2006.

[10] J. L. Dong, Q. S. Li, and S. Ma, "A research of anion rubber modified asphalt," Heilongjiang Science and Technology Information, vol. 26, p. 85, 2011.

[11] S. L. Daniels, “"'On the ionization of air for removal of noxious effluvia" (air ionization of indoor environments for control of volatile and particulate contaminants with nonthermal plasmas generated by dielectric-barrier discharge)," IEEE Transactions on Plasma Science, vol. 30, no. 4 I, pp. 1471-1481, 2002.

[12] W. Hong, Q. S. Li, and G. Q. Quan, "Pavement performance and application of anion rubber-modified asphalt," Chinese Science Bulletin, vol. 57, no. 18, pp. 2323-2328, 2012.

[13] Highway Asphalt Pavement Construction Technical Standard, JTGF40-2004, China Communications Press, Beijing, China, 2004 (Chinese).

[14] The Test Criterion for Highway Project Pitch and Pitch Compounds, JTJ052-2000, China Communications Press, Beijing, China, 2000, (Chinese).

[15] D. Wang, Guide for Design and Construction of Asphalt Rubber and Mixture, China Communications Press, Beijing, China, 2008 (Chinese). 

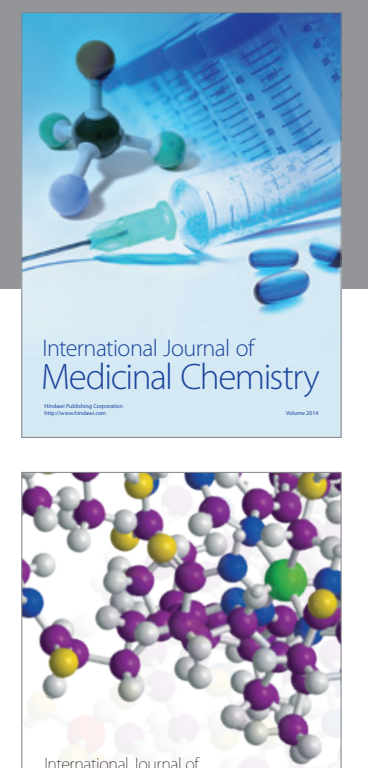

\section{Carbohydrate} Chemistry

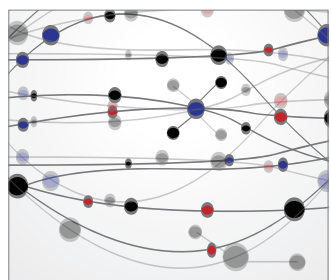

The Scientific World Journal
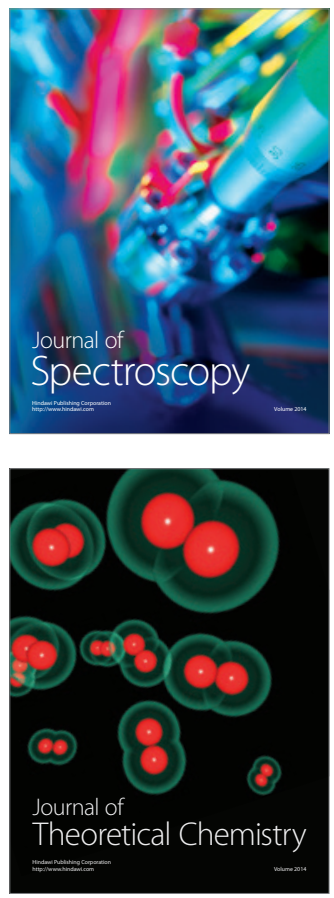
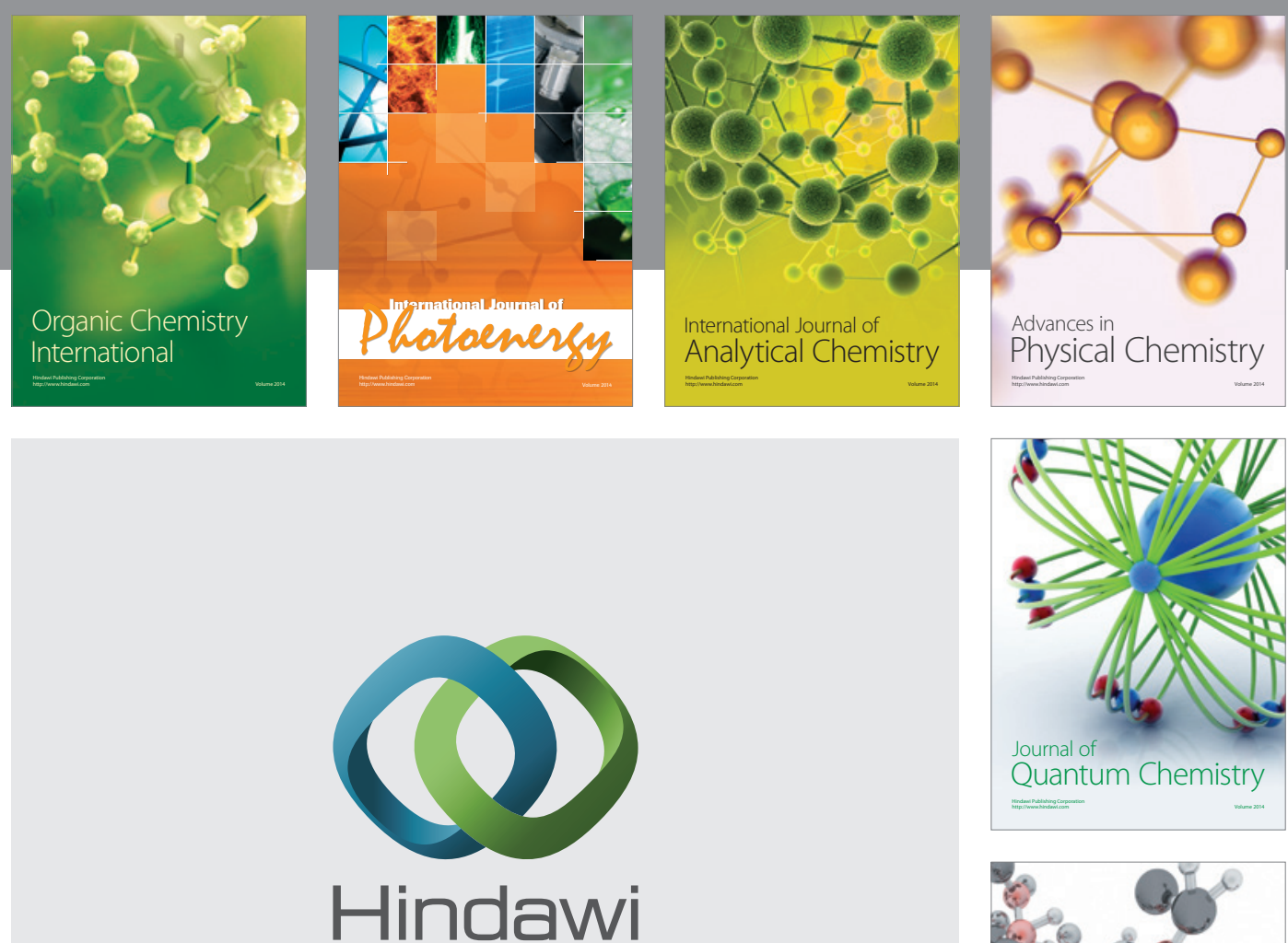

Submit your manuscripts at

http://www.hindawi.com

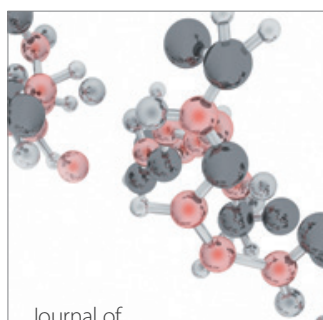

Analytical Methods

in Chemistry

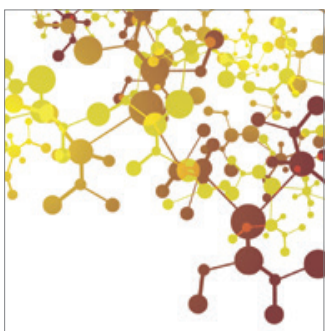

Journal of

Applied Chemistry

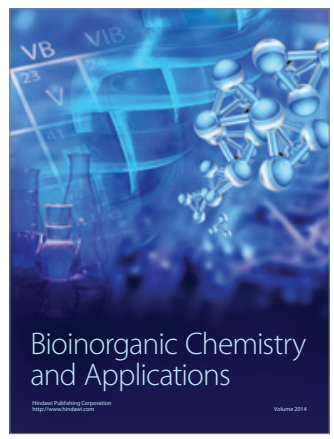

Inorganic Chemistry
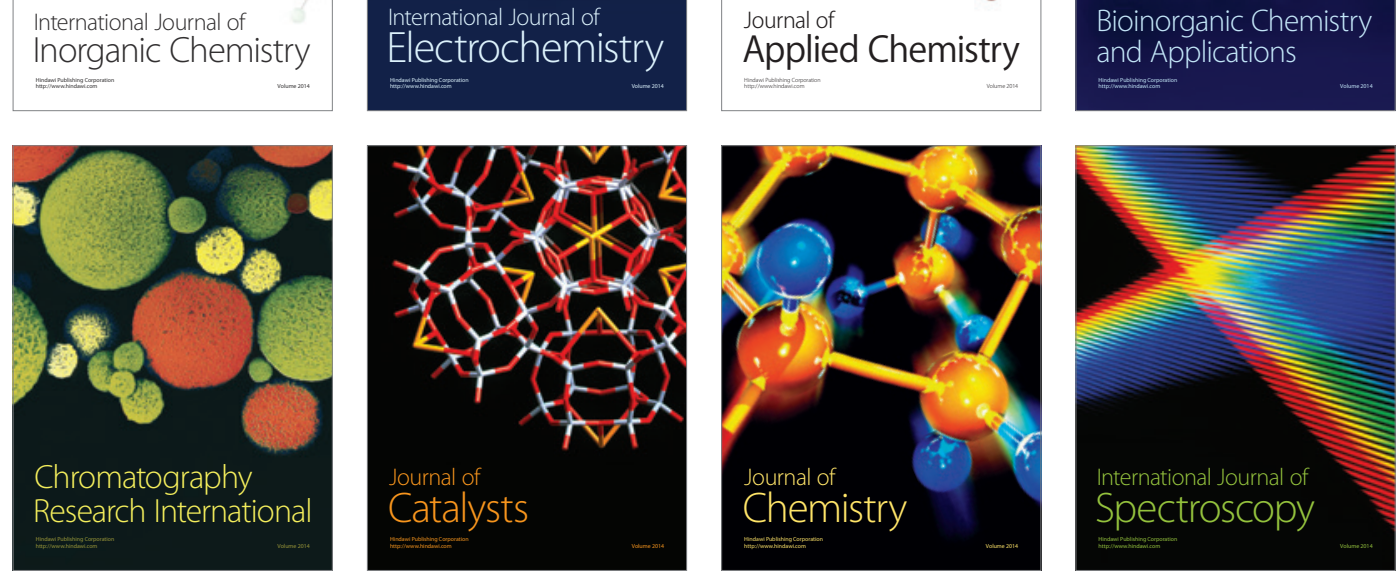